2017-09-11

Racism, Prevent and education: insisting on an open space

Haynes, Joanna

http://hdl.handle.net/10026.1/9925

10.1108/SC-05-2017-0020

Safer Communities

emerald insight

All content in PEARL is protected by copyright law. Author manuscripts are made available in accordance with publisher policies. Please cite only the published version using the details provided on the item record or document. In the absence of an open licence (e.g. Creative Commons), permissions for further reuse of content should be sought from the publisher or author. 
This is the authors' accepted manuscript. The final published version of this work (the version of record) is published by Emerald Insight in Safer Communities in September 2017 available at: https://doi.org/10.1108/SC-05-2017-0020.

This work is made available online in accordance with the publisher's policies. Please refer to any applicable terms of use of the publisher.

\title{
Racism, Prevent and education: insisting on an open space
}

Joanna Haynes, Plymouth Institute of Education joanna.haynes@plymouth.ac.uk

Rowena Passy, Plymouth Institute of Education R.Passy@plymouth.ac.uk

\begin{abstract}
In this article we first discuss the Brexit referendum and its links to changes in the nature of racism in England, drawing on Burnett's (2013) work to demonstrate how 'local conditions, national politics and global conditions' have prompted violent racism in new areas of the country. Within this atmosphere of heightened tension, anti-Muslim abuse and attacks have risen over the past two years, with a proportion of these incidents taking place in universities. We then examine the implications of the counter-terrorist Prevent agenda, arguing that educators' statutory duty to 'have due regard to the need to prevent people from being drawn into terrorism' is in considerable tension with the university statutory duty to uphold freedom of speech/academic freedom; this 'duty of care' effectively requires university staff to act as agents of the state. We argue that this threatens to damage trust between staff and students, restrict critical enquiry and limit discussion, particularly in the current circumstances of sector insecurity that have arisen from a combination of neoliberal policies and falling student numbers. We then examine disturbing trends that characterise students as vulnerable and university life as potentially damaging to well-being, and how these link to anti-extremism dialogue that is expressed in epidemiological and therapeutic language; the vulnerable are framed pathologically, as 'at risk' of radicalisation. Developing the argument on how these conditions present a threat to freedom of speech/academic freedom, in the final section we argue that universities must keep spaces open for uncertainty, controversy and disagreement.
\end{abstract}

\section{Introduction}

This article arises from the Brexit: Crime, Justice and Society conference held at Plymouth University in April 2017. The reaction to the presentation, in which delegates showed a deep interest in the issues we were raising, together with the invitation to contribute to this Special Issue, encouraged us to write this position piece in the short time available. In what follows we have further developed our initial ideas about the connections between Brexit, racism, the Prevent agenda, discourses around student vulnerability, and their effects on higher education. 


\section{Context: the times we're in}

The Brexit referendum in June 2016 appeared to unleash a renewed polarisation within British society, seen particularly in an 'emboldened' and 'celebratory' racism (Bagguley cited in Kaheeli, 2016) that framed immigrants and refugees as the enemy that needs to be expelled or kept out of Britain. While the rise of such views from (often) the political far right can also be seen in Europe (Chakelian, 2017), British media reports at the time of the referendum showed a spike in racism and hate crime (e.g. Chakrabortty, 2016; Kaheeli, 2016; Versi, 2016), and this was supported by subsequent analysis of crime statistics that demonstrated an increase of 41 per cent in incidents of racist or religious abuse in the month following the vote (BBC, 2016). Such reports need to be treated with caution, but it was notable that the Brexit campaign included considerable racist and xenophobic rhetoric, which presents the possibility that the referendum was a kind of 'trigger' event that can 'galvanise tensions and sentiments' (Awan \& Zempi, 2015, p.9) against those who seemingly have a different heritage. More cautiously, perhaps, Ford and Goodwin (2017) argue that the campaign stimulated a 'high-profile and deeply polarizing debate' over issues such as identity, nationalism, social values and social change (p.28) and that it 'exposed and deepened a ... set of cleavages that are largely cultural' (p.29).

These views of divisions within British society may partially be explained by Bagguley's (2016) suggestion that, over the last decade, a central part of anti-European Union discourse in the British media has been a sense that Britons are different to other Europeans, and that this has given rise to a generalised type of racism that is aimed at those who are perceived to be outside the category of 'white English' (cited in Kaheeli, 2016). However Sivanandan (1989 cited in Taras, 2013, p.422) comments that

... racism never stands still. It changes shape, size, contours, purpose, function, with changes in the economy, the social structure, the system and, above all, the challenges, the resistances, to that system (Sivanandan, 1989 cited in Taras, 2013, p.422).

Burnett (2013) argues that violent racism has been 'spreading' from major cities in the UK to areas that previously had no such history (p.3), and that this needs to be understood in terms of the interaction between 'local realities, national politics and global conditions' (p.4). He contends that demographic changes, in which 'new' migrants find themselves in cities or areas that until recently have had a majority white British population, have resulted in racist attacks against asylum seekers, migrant workers and international students. More established communities, such as Muslims, have also been targeted, largely through hostility generated by the so-called 'war on terror'. He suggests that that ideas of multiculturalism undermining national identity, of Britain becoming overwhelmed by migration, and of migrants' perceived responsibility for local economic difficulties have taken hold in the media, thereby legitimising the core racist, anti-immigration messages of the political far right. He argues that in response, more mainstream political parties have competed to demonstrate their strength on issues connected to asylum, immigration and race, which has 
deepened hostility around these issues. And, since 2010, austerity politics have widened economic inequalities within and between localities, and have reduced the number of, and available expertise in, advice and support centres around the country for those targeted by racist abuse. This has left individuals, including students, and families isolated and vulnerable, without access to the type of established support structure that have been developed over years within larger, industrial cities that experienced earlier waves of immigration (Burnett, 2013, pp.4-6).

Within this environment of heightened fear and tension, the organisation Tell MAMA (2016) reports that incidents of anti-Muslim abuse and attacks in public areas of the UK rose by over 300 per cent in 2014/5, with women disproportionately targeted. Their findings are supported by a recent Taskforce report on hate crime in universities (UUK, 2016), which demonstrates that Muslim women are particularly likely to experience hate crime on campus:

Evidence submitted to the Taskforce suggested that a rise in religious and race hate crime, exacerbated by a wider climate of anti-Muslim hate crime and harassment, means that female Muslim students are at greater risk of attacks. The NUS Black Students' Campaign also stated that $72 \%$ of Muslim women have experienced verbal abuse and threatening behaviour relating directly to their visible Muslim presence' (UUK, 2016, p.26).

Solutions for the Taskforce lie in reporting, supporting and monitoring systems within individual universities, with an emphasis on the 'duty of care' within higher education institutions (HEIs). It is important to remember, however, that one important aspect of any university's duty of care stems from the Counter-Terrorism and Security Act (HM Government, 2015a, Section 26) which, since September 2015 and as part of the 'Prevent' counter-terrorist agenda, has placed a statutory duty on UK universities to 'have due regard to the need to prevent people from being drawn into terrorism'. The Prevent agenda has been controversial from its instigation; as part of the government's counter-terrorism strategy, launched originally in 2007 in response to the 2005 terrorist bombings in London, it was initially widely criticised for the lack of clarity in its aims, and for its divisive effects both between Muslim and other communities and within the different Muslim communities in Britain (e.g. Kundnani, 2009; Thomas, 2010, 2017). Following a review under the Coalition government (HM Government, 2011) the current iteration has presented university frontline staff with a difficult situation in which they are "responsibilised' for spotting radicalisation' (Thomas, 2017, p.315) while upholding the other statutory duty to promote academic freedom and freedom of speech.

In the following sections, we examine these two duties and the tensions between them, arguing that this creates distinctive issues for the higher education sector. We then explore the idea of student vulnerability, both in terms of the narrative of the contemporary student and the student 'at risk', contextualising these tensions in the wider climate of an 
increasingly marketised higher education environment. We argue that, despite the potential difficulties of creating and maintaining an environment conducive to discussion and deliberation, this conjuncture provides new opportunities to sustain the open and dialogical space that should characterise good quality higher education.

\section{Policy and precariousness: insecurities within the academic community}

The HEI Guidance to the Prevent legislation (HM Government, 2015b, p.5) states that governmental concern about students' potential to be drawn into terrorism includes 'not just violent extremism but also non-violent extremism, which can create an atmosphere conducive to terrorism and can popularise views which terrorists exploit'. The details of how and what to identify, however, are left unspecified in the Guidance, other than noticing 'changes in [students'] behaviour or outlook' (HM Government, 2015b, p.4), while the extremism in a more general Guidance publication is defined as 'vocal or active opposition to fundamental British values, including democracy, the rule of law, individual liberty and mutual respect and tolerance of different faiths and beliefs' (HM Government, 2015c, p.2). The whole gives the impression of a porous set of ideas about what might constitute extremism (of any kind) and how it could be identified, leaving higher education institution (HEI) staff positioned as important frontline staff against the threat of terrorism but with an uncertain conceptual or practical framework within which to carry out these duties.

It is noticeable in this context that the university statutory duty to uphold freedom of speech/academic freedom is mentioned in passing in these documents. In the HEI Guidance, for instance, upholding these freedoms is mentioned only in relation to the question of inviting external speakers, suggesting that HEls should 'consider carefully whether the views being expressed, or likely to be expressed, constitute extremist views that risk drawing people into terrorism or are shared by terrorist groups' (HM Government 2015b, p.4). However, Saeed and Johnson (2016, p.40) suggest that the Prevent-related duty of care 'trumps the possibility' of academic freedom in practice. They argue that the duty of care relating to extremism is 'in direct contradiction' to the Education Reform Act of 1988, which states the importance of ensuring that academic staff have the freedom to test received wisdom, put forward new and controversial ideas or unpopular opinions 'without placing themselves in jeopardy of losing their jobs or privileges they may have at their institutions' (HM Government, 1989, cited in Saeed \& Johnson, 2016, p.40).

In a burgeoning body of critical literature relating to the Prevent legislation and agenda, a number of commentators (e.g. McGovern, 2016; O'Donnell, 2016a; Thomas, 2017) have argued that the Prevent strategy amounts to HEl staff being charged with the responsibility of identifying and reporting on people who have committed no crime and who may (or may not) be currently involved in some kind of 'non-violent extremism', or who may potentially be involved in some kind of extremism or terrorism in the future. These authors suggest that placing this duty of care within the realms of pre-crime - rather than committed crime - has profound implications for both staff and students. Neither of these groups can be certain about the boundaries of what it is acceptable to say within the context of their work and 
study, and both O'Donnell (2016a) and McGovern (2016) argue that this uncertainty, together with the positioning of HEI staff effectively as agents of the state, will have the consequence of destroying trust, restricting inquiry and limiting discussion. Indeed, researchers are beginning to find that Religious Education initial teacher education students are limiting their engagement with issues related to racism, culture and faith (Elton-Chalcraft et al, 2017) and that Muslim students are self-censoring because of the environment of mistrust within their HEls (Saeed \& Johnson, 2016). This early research demonstrates the practical difficulty of balancing the duty of upholding freedom of speech/academic freedom with the duty of care to students and staff, and seems to support Saeed and Johnson's view that the duty of care trumps that of upholding freedom of speech. But it also gives rise to questions about the prevalent conditions within HEls that can - and do - influence staff and student responses.

McGovern (2016) argues universities are becoming increasingly risk-averse as neoliberal policies of marketisation and privatisation have shifted towards HEIs, and that the Prevent agenda will deepen what he refers to as 'cultures of compliance' (2016, p.49). We agree, and suggest that some of the symptoms of neoliberal policies experienced by schools in England and elsewhere are now spreading to the HEI sector; just as choice, competition and privatisation in the school sector have led to new forms of accountability to state, school managers, parents and pupils (Passy, 2013), so universities are discovering the implications of developing and implementing marketing strategies, of the impact of so-called 'league tables' and of providing government-required, publicly accessible data on such issues as student employability. These include increasing amounts of time spent on bureaucratic procedures such as lesson planning; different kinds of pupil data and teacher performance data in schools are reflected in university requirements that staff monitor student attendance, collect data around teaching quality (increasingly so in anticipation of the Teaching Excellence Framework) and cope with complex information technology systems that are aimed at making all processes visible and accessible. While none of this is necessarily a bad thing per se, the amounts of time involved sap energy (e.g. NASUWT, 2016; NUT, 2014) that would be more productively harnessed to, for instance, creative mediation of the two potentially conflicting duties discussed above.

At the same time, universities are also experiencing a collective insecurity on a number of different levels. First the so-called demographic dip, in which fewer young people in the country mean a diminished number of potential students (Fazackerly, 2017), coupled with fears relating to fewer permitted international students as a means of reducing governmentimposed levels of immigration (Foster, 2017) and the repercussions of Brexit on student numbers, are causing HEls across the country to reduce staffing levels, sometimes drastically (Pidd, 2017). This institutional insecurity is mirrored in university staff, who are rightly concerned about the uncertainty of their employment, and in university students, who are no longer guaranteed a smooth passage from university to graduate-level jobs (Brown et al, 2011; Standing, 2015), giving rise to a kind of collective anxiety in which it is simply easier to keep one's head down rather than open up possible avenues for controversy or discord. 
We argue that most people need an element of security in order to function as confident, independent thinkers who are unafraid of taking possible risks, whether they are university staff - who need to create an atmosphere of trust in which all are free to question, to discuss controversial topics and to be uncertain about knowledge, and who have the responsibility to carry out research on controversial or unpopular issues - or students, who need to feel secure enough to participate in potentially risky discussions without jeopardising their marks or prompting greater surveillance of their actions.

This combination of increased workload and an insecure academic community, when taken in the context of the social and political trends discussed in the first part of this article, are precisely the conditions in which the inherent tensions between the duty to uphold freedom of speech/academic freedom and the Prevent-related duty of care can become magnified. In addition any 'cultures of compliance' (McGovern, 2016, p.49) can become more pronounced. The issue is given further complexity by individual universities' approach to implementing the Prevent-related duty of care, exemplified by Olohan et al's (2015) presentation at a Universities UK Prevent conference, in which they examine the tensions between the different agendas of the different agencies involved in Prevent in HEls. The central question for this presentation is who leads the implementation process: if led by university security, the authors argue that the process will focus primarily on security; if led by registry, they claim it will focus on compliance; if led by student services, they suggest it will focus on safeguarding and community cohesion. This potentially brings in new levels of institutional uncertainty and adds a further layer of ambiguity around the working relationships between students and HEl staff.

In the following section, we consider shifts in these relationships by examining discourses around student welfare, the practices that they engender, and how staff and students are positioned within these discourses. We then discuss the implications for staff and student critical engagement in HEls.

\section{Care and concern in the 'total' university community}

As student bodies have become more diverse in terms of age and background over the past 30 years or so, and as students have increasingly managed their studies alongside other roles such as carers and workers, HEls have had to reconsider the role and extent of student support (Jacklin \& le Riche, 2009). The variety and complexity of students' lives, in which they balance such demands within a competitive and precarious economic climate, have shifted the terms of relationships between students and academic staff. There are growing pressures for staff to be more aware of, and to address any additional pressures on students, particularly as they have become consumers of higher education and are accumulating large debts in order to complete their studies. Within this context, we suggest that academics are increasingly positioned as providers of 'extra' care, not only from the Prevent-related duty discussed above, but also from the wider case that is currently being made - with growing purchase - that student wellbeing in general, and their mental health in particular, is a cause for wider concern. Statistics indicate that the percentage of the student 
population affected is small, at 0.8 per cent in total in 2013 (UUK, 2015, p.5), but 27 per cent of students responding to a recent survey reported that they had experienced a mental health condition while at university, with depression and anxiety the most frequently cited (YouGov UK, 2016). More recently Marsh (2017) reports on the rapidly increasing dropout rate of university students on grounds of poor mental health, citing the Higher Education Statistics Agency finding of 1,180 students experiencing mental health problems and leaving university early in 2014/5, a rise of 21 per cent on figures for 2009/10. Marsh also reports a large rise in the numbers of students seeking counselling, and draws on quotations from former health minister Norman Lamb to underscore the sense of increased pressure on university counselling services as an unfolding crisis. What is particularly pertinent for this paper, in terms of the positioning of students as vulnerable and in need of protection and of academics as needing to be alert to students' mental health, is the reported view of a student health GP cited in the article:

Dominique Thompson, a student health GP, said she feared students could be leaving early as they struggled to cope with the gulf between school teaching and university education (Marsh, 2017).

What is the 'gulf' to which this article alludes? A Universities UK report attributes the growth in mental health issues in part to student life being a time of greater transition, change, encounters with different cultures and financial strain (UUK, 2015). We believe that it is important to recognise the particular pressures on the current generation of students. It is also vital to examine how a particular narrative of stress might lead to overly pessimistic conclusions about students' general wellbeing and capacity to engage with university learning. While it is evident that the enormous burden of debt on students is growing and financial constraints are exerting different kinds of pressures, the notion of encounter with change and difference as a 'risk factor' in mental wellbeing is contestable. To contest this view is not to question the provision of good services to students with mental health issues, nor the accuracy of the reported increase of such conditions. However, the notion of such a 'gulf' and problematic encounter with the new is at odds with the idea of university education as adult education; as an opportunity for broadening of intellectual and social horizons, and finding a way in the world in dialogue with others. Appearing to characterise students as mentally fragile and generally insecure can be a powerful (and probably unhelpful) framework for those starting or engaged in university studies.

Positioning students as (young) people who need ever higher levels of guidance and oversight also suggests that all staff should be fully alert to the 'signs' of potential vulnerability and know what course of action to take, thereby indicating expectations about the kinds of services available in the university community. The same GP cited in Marsh's (2017) article discussed above suggests that the solution lies in providing increased access to relevant study skills, alongside a wide range of mental health and wellbeing options; a kind of supermarket of total services. While we are not denying the importance of these services, we are arguing that notions of student fragility and of university life as 'dangerous' 
present a wider threat to academic freedom and open discourse that are historically at the core of university education. This is a situation perhaps unwittingly exacerbated by the accountability measures taken by HEI staff to demonstrate students' satisfactory engagement with their studies, which Macfarlane (2015) argues reduces student autonomy and freedom, and has a negative effect on students' rights and capacity

... to choose how to use study time, to learn as individuals, to speak or be reticent, and to develop their own ideas and values (Macfarlane, 2015, p.339).

It is important to recognise how this wider narrative of stress and vulnerability, if accepted without question, shapes epistemic relations in the university setting. If student fragility is placed in the foreground of academics' concerns, it has the potential to have negative effects on the ways in which they regard students in their capacities as knowers. The so-called and generalised 'vulnerability' of young people and of students to new and different knowledges, and the powerful emotions that they might arouse, appears to have become deeply embedded in the discourses and culture of education, including in the Prevent policies discussed above. The idea of radicalism itself has become tainted with implications of psychological imbalance and disconnected from the search for new ideas to address social and worldly ills. We could say that it is a concept that has been appropriated (Sukarieh \& Tannock, 2016). O'Donnell (2016b) suggests this results in a silencing of dissent, and she questions the ways in which anti-extremism discourse is expressed in epidemiological and therapeutic language: the 'vulnerable' are framed pathologically, as 'at risk' of radicalisation. Such 'vulnerability' has an elusive quality, as it refers to a future potential risk, rather than a tangible and present danger. Extremist ideas are portrayed as highly contagious viruses that spread easily and take hold; students and young people, particularly from Muslim communities, are regarded as more likely to be 'infected'. The vulnerable student is characterised as a diminished subject, whose capacity to resist infection, now or in the future, is reduced by virtue of youth, instability, or religious and cultural association. O'Donnell argues that Prevent constitutes a pedagogical and epistemic injustice, by denying credibility to those who contest it and by constructing racialized frameworks that present Muslims as routinely suspect. Muslim students, and others, are subjected not only to stereotyping, but are further denied credibility or the capacity for political dissent, on the grounds of that stereotyped identity. She also argues that Prevent is anti-educational because it 'securitises' education (2016a, p.2); by framing the Prevent duty of care as safeguarding the community, academics are positioned not only as guardians and protectors, responsible for identifying the 'symptoms' of vulnerability, but also in the frontline of intelligence gathering. It is easy to see how such framing might lead to self-censorship and silencing, and contribute towards a wider climate of anxiety, distrust and suspicion between students and staff.

In his review of Prevent policy enactment in schools and FE colleges, Thomas (2017) argues that readings of its enactment have to be carefully nuanced and take into account the 
'engaged contestation' (2017, p.306) by, for example, front line professionals, Muslim organisations and trade unions. Thomas argues 'the day-to-day lived reality of educational experience can often look and feel significantly different from the picture painted in elite-level policy discourse, thanks to the ways that ground-level institutions like schools interpret and 'enact' these top-down policy strictures' (2017, p.311). There is clear opposition to the Prevent agenda from education unions (e.g. UCU, 2015), Muslim organisations such as the Muslim Council of Britain (MCB, 2015) and, as we have seen above, from members of the academic community. All argue that the policy discriminates against Muslims and that it stifles freedom of speech. The distinctive space of dissension at Prevent's ground level enactment in higher education policy contexts post-Brexit, together with the responses of academics and of student societies and unions, are issues that we argue require further research. As a preliminary, this paper has mapped out some of the prevailing policy strictures and discourses.

In order to stay in business, universities are competing for students, and the competition is intense (Doward \& Ratcliffe, 2016). The expansion of the HE sector has taken place under the banner of widening participation and upward social mobility. Marketing departments are driven by the need to portray a distinctive experience for students: a 'total' and good value package for money that will manage not only the 'delivery' of academic courses, but housing, health and well-being, employability and a bright future. In this new culture of extra care in universities, pastoral relationships between academics and students are increasingly imbued with a marketised version of the 'student experience', with promises of active participation, success and upward social progress. Academics, already worried about their job security, are expected to micro-manage this student experience, arguably drawing their energies and attention away from the core activities of teaching and research. It is important to note these features of the higher education market, and the additional uncertainty Brexit has created for European and international students and staff. At the same time, the political climate is a rapidly changing and fluid one, and the challenge to neo-liberal values appears to be gaining momentum, including in relation to higher education in the UK, where we have recently seen calls to account for vice chancellors' levels of pay (Adams, 2017) and for the abolition of student fees (Mason, 2017) and mitigation of student debts (Walker, 2017). On the other hand, in a speech on delivering value for taxpayers and students, Jo Johnson, the current Minister of State for Universities, Science, Research and Innovation, has suggested students would get better value for money through the introduction of (neo-liberal) contracts between students and universities that specify the details of their university education (Johnson, 2017). In the light of this dispute over policy and the political fluidity of Brexit negotiations, Thomas's (2017) call to closely observe and note contestation and ground level enactment of policy seems particularly pertinent and well advised. In the following section, we turn to consideration of ground level responses and pedagogies that might offer holding grounds or antidotes to the kind of insecurities that are circulating.

\section{Critical engagement in higher education}


The creation of 'safe spaces' in higher education is important for critical engagement with sensitive and controversial topics, including those associated with Prevent. However it is also a troublesome idea because there is always a tension between maintaining students' confidence and willingness to explore difficult ideas and the rights of tutors and students to challenge each others' beliefs and views, and the idea of what constitutes a safe space is contested. This has recently provoked considerable public debate in the press. On the one hand former NUS president Malia Bouattia defends the policy of 'no platform' for racist, xenophobic and homophobic speakers on campus, arguing that the policy is necessary to preserve safe spaces on campus, where students are free from threat or intimidation (Bulman, 2016). On the other hand, this particular interpretation of safe spaces has been attacked in the House of Commons by UK Prime Minister Theresa May as undermining not only free speech but also posing a threat to innovation in the interests of social and economic progress. May describes freedom of expression as a fundamental British value (Mason, 2016). However, the same government is responsible for the Prevent legislation and guidance around that legislation, offering - at best - mixed messages about how to enact that freedom of expression. There is the risk that silence, avoidance, overreaction or tension are increasingly likely as staff and students grapple with concepts such as protection, extremism and radicalisation within the context of the staff legal obligation to identify and report those vulnerable to extremism. These trends represent a real and unevenly distributed threat to the rights of students to speak and of others to hear them speak in the university classroom. We suggest that these conditions are not conducive to open and critical engagement and consequently present a threat to academic freedom and freedom of speech.

Critical enquiry and engagement are typically associated with courage, openness, robustness and the normalisation of passionate expression and disagreement. On the other hand, the provision of a safe classroom can elicit notions of caution, protection and control within the context of student vulnerability. Staff and students' capacity to be comfortable with uncertainty seems to be at the heart of this issue. Critical enquiry relies on the free expression of perspectives and on uncertainty and doubt in the face of strongly held ideas, beliefs and values. However, as Chetty (2017) has pointed out, under the Prevent guidelines some varieties of doubt seem to be automatically suspect and indicative of unsound mind. What kinds of culture, relationships and teaching expertise do these real and present dilemmas about freedom of expression demand? What is the antidote to insecurity and vulnerability? We want to argue that much greater attention and resource needs to be given to the kind of pedagogical knowledge and conditions required to keep the space of robust and confident critical dialogue open in university classrooms and on campus, and that this is a question to mobilise the interests of students and staff alike.

O' Donnell (2017) argues that, unlike indoctrination, education is all about critical enquiry, exploring and questioning a range of different ideas in order to come to a deep understanding of a given subject (O'Donnell, 2017). She further suggests that educators are committed to creating the conditions for contestation in classrooms, but cautions that this is 
troublesome when education institutions are required to justify and shape their practice with direct reference to a security agenda (O'Donnell, 2017). Embracing doubt and uncertainty as essential aspects of education can be seen as the first step in creating conditions for disagreement, for uncertainty is a close relative of curiosity. Naturalising disagreement and contention is a further step in keeping the space of free expression open, and should become an ingrained habit. Similarly, becoming familiar with emotional upheaval and learning to value the power of negative affect to inform and illuminate both our thinking and understanding of the most pressing issues of our times are important aspects of the educative process (Shotwell, 2011).

\section{Conclusion}

Our discussion has shown how different current trends and discourses in contemporary Britain that relate to Brexit, racism, the marketisation of higher education and perceptions of student vulnerability are changing the nature of the relationship among $\mathrm{HEI}$ staff and students, and potentially closing down the spaces for open discussion on sensitive and controversial issues. The tension between the statutory duty of HEI staff to report people that they believe to be at risk of radicalisation needs to be examined and mediated with the statutory duty of upholding academic freedom and freedom of speech to avoid any further reduction in the willingness of all to engage with difficult issues in university classrooms. This would reduce the richness of a university education in which students should have the opportunity to explore, examine and experiment with ideas and issues; to engage critically with each other and the world around them, and to experience at a practical level the democratic processes of dialogue and discussion - all of which help to encourage a wellinformed, thoughtful and politically-engaged citizenry. For these reasons, it is essential that we strive to keep these spaces open for uncertainty, controversy and disagreement in HEls.

\section{References}

Adams, R. (2017) University vice-chancellors are paid too much, says Lord Adonis, Guardian, 13 July. Online: https://www.theguardian.com/education/2017/jul/13/universityvice-chancellors-are-paid-too-much-says-lord-adonis (accessed 21.07.2017).

Awan, I. \& Zempi, I. (2015) We Fear for our Lives: Offline and Online Experiences of AntiMuslim Hostility, Birmingham City University, Nottingham Trent University, Tell MAMA. Online: https://tellmamauk.org/wp-content/uploads/2017/05/We-Fear-For-Our-Lives.pdf (accessed 03.05.2017).

BBC (2016) Race and religious hate crimes rose $41 \%$ after EU vote, 13 October. Online: http://www.bbc.co.uk/news/uk-politics-37640982 (accessed 03.05.2017).

Brown, P., Lauder, H. \& Ashton, D. (2011) The Global Auction: the broken promises of education, jobs and incomes, Oxford: Oxford University Press. 
Bulman, M. (2016) NUS president Malia Bouattia defends safe spaces and no platforming at UK universities, Independent, 27 September. Online:

http://www.independent.co.uk/news/education/education-news/nus-president-malia-bouattiadefends-safe-spaces-no-platforming-universities-a7333171.html (accessed 24.05.2017).

Burnett, J. (2013) Racial Violence: facing reality, Institute of Race Relations. Online: http://s3-eu-west-2.amazonaws.com/wpmedia.outlandish.com/irr/2017/04/26155304/Racialviolence-facing-reality.pdf (accessed 04.05.2017).

Chakelian, A (2017) Rise of the nationalists: a guide to Europe's far-right parties, New Statesman, 8 March. Online: http://www.newstatesman.com/world/europe/2017/03/risenationalists-guide-europe-s-far-right-parties (accessed 21.07.2017).

Chakrabortty, A. (2016) After a campaign scarred by bigotry, it's become OK to be racist in Britain, Guardian, 28 June. Online:

https://www.theguardian.com/commentisfree/2016/jun/28/campaign-bigotry-racist-britainleave-brexit (accessed 03.05.2017).

Chetty, D. (2017) Controversy, Safety and Values - Reflecting on Philosophy for Children and the Prevent Strategy. Presentation to SAPERE seminar, Aston University Conference Centre, 27 January.

Doward, J. \& Ratcliffe, R. (2016) UK universities take increasing battle for students into virtual world, Observer, 13 August. Online:

https://www.theguardian.com/education/2016/aug/13/uk-universities-take-increasing-battlefor-students-into-virtual-world (accessed 22.05.2017).

Elton-Chalcraft, S., Lander, V., Revell, L., Warnera, D. \& Whitworth, L. (2017) To promote, or not to promote fundamental British values? Teachers' standards, diversity and teacher education, British Educational Research Journal, 43:1, 29-48, DOI: 10.1002/berj.3253.

Fazackerley, A. (2017) What would happen if a UK university went bust? Guardian, 7 February. Online: https://www.theguardian.com/education/2017/feb/07/what-if-uk-universitygoes-bust-ucas-students (accessed 23.05.2017).

Ford, R. \& Goodwin, M. (2017) Britain after Brexit: a nation divided, Journal of Democracy, 28 (1), 17-30, DOI: https://doi.org/10.1353/jod.2017.0002.

Foster, D. (2017) Theresa May's manifesto shows that she is more right wing than Cameron ever dared to be, Independent, 18 May. Online:

http://www.independent.co.uk/voices/theresa-may-tory-manifesto-2017-david-cameron-rightwing-social-care-a7743146.html (accessed 23.05.2017). 
HM Government (2015a) Counter-Terrorism and Security Act. Online:

http://www.legislation.gov.uk/ukpga/2015/6/part/5/enacted accessed 12.05.2017.

HM Government (2015b) Prevent Duty Guidance: for higher education institutions in England and Wales. Online:

https://www.gov.uk/government/uploads/system/uploads/attachment data/file/445916/Preve nt Duty Guidance For Higher Education England Wales .pdf (accessed 12.05.2017).

HM Government (2015c) Revised Prevent Duty Guidance: for England and Wales. Online: https://www.gov.uk/government/uploads/system/uploads/attachment data/file/445977/3799 Revised Prevent Duty Guidance England Wales V2-Interactive.pdf (accessed 12.05.2017).

HM Government (2011) Prevent Duty. Online:

https://www.gov.uk/government/uploads/system/uploads/attachment data/file/97976/prevent -strategy-review.pdf (accessed 21.07.2017).

Jacklin, A. \& Le Riche, P. (2009) Reconceptualising student support: from 'support' to 'supportive', Studies in Higher Education, 34:7, 735-749, DOI:

10.1080/03075070802666807.

Johnson, J. (2017) Delivering value for money for students and taxpayers, speech to higher education sector, 20 July. Online: https://www.gov.uk/government/speeches/jo-johnsondelivering-value-for-money-for-students-and-taxpayers (accessed 21.07.2017).

Kaheeli, H. (2016) A frenzy of hatred: how to understand Brexit racism, Guardian, 29 June. Online: https://www.theguardian.com/politics/2016/jun/29/frenzy-hatred-brexit-racism-abusereferendum-celebratory-lasting-damage (accessed 03.05.2017).

Kundnani, A. (2009) Spooked! How not to prevent violent extremism. Online: http://www.irr.org.uk/news/spooked-how-not-to-prevent-violent-extremism/ (accessed 21.07.2017).

Macfarlane, B. (2015) Student performativity in higher education: converting learning as a private space into a public performance, Higher Education Research and Development, 34:2, 338-350, DOI: 10.1080/07294360.2014.956697.

Marsh, S. (2017) Number of university dropouts due to mental health problems trebles, Guardian, 23 May. Online: https://www.theguardian.com/society/2017/may/23/numberuniversity-dropouts-due-to-mental-health-problems-trebles (accessed 23.05.2017). 
Mason, R. (2017) Labour pledges to abolish tuition fees as early as autumn 2017, Guardian, 21 May. Online: https:/www.theguardian.com/education/2017/may/21/labour-abolishuniversity-tuition-fees-jeremy-corbyn-eu-uk-europe (accessed 21.07.2017).

Mason, R. (2016) Theresa May criticises university 'safe spaces' for shutting down debate, Guardian, 14 September. Online:

https://www.theguardian.com/education/2016/sep/14/theresa-may-criticises-university-safespaces-for-shutting-down-debate (accessed 24.05.2017).

McGovern, M. (2016) The university, Prevent and cultures of compliance, Prometheus, 34:1, 49-62, DOI: 10.1080/08109028.2016.1222129.

Muslim Council of Britain (2015) Concerns on Prevent. Online: https://www.mcb.org.uk/wpcontent/uploads/2015/10/20150803-Case-studies-about-Prevent.pdf (accessed 25.05.2017).

NASUWT (2016) Excessive Workload - The facts 2016. Online:

https://www.nasuwt.org.uk/uploads/assets/uploaded/4b119d25-653b-4e61-

be50181dd388d7cd.pdf (accessed 18.05.2017).

National Union of Teachers (2014) Teachers and Workload. Online:

https://www.teachers.org.uk/files/teachers-and-workload-survey-report-september-2014.pdf (accessed 25.05.2017).

O'Donnell. A. (2017) Pedagogical injustice and counter-terrorist education. Education, Citizenship and Social Justice, available as Online First:

http://journals.sagepub.com/doi/pdf/10.1177/1746197917698490 (accessed: 22.05.2017).

O'Donnell, A. (2016a) Contagious ideas: vulnerability, epistemic injustice and counterterrorism in education, Educational Philosophy and Theory, published online 16 December, http://dx.doi.org/10.1080/00131857.2016.1217187.

O'Donnell, A. (2016b) Securitisation, Counterterrorism and the Silencing of Dissent: The Educational Implications of Prevent, British Journal of Educational Studies, 64(1), 53-76, DOI: 10.1080/00071005.2015.1121201.

Olohan, S., Carey, J. \& Slack, S. (2015) Partnership Working: Managing the Tensions: A student services perspective, UUK. Online:

http://www.slideshare.net/UniversitiesUK/partnership-working-managing-the-tensions-astudent-services-perspective (accessed 11.05.2017).

Passy, R. (2013) Surviving and flourishing: primary trainees talking, British Educational Research Journal, 39:6, 1060-1075, DOI: 10.1002/berj.3024. 
Pidd, H. (2017) University of Manchester to axe 171 staff amid Brexit concerns, Guardian, 10 May. Online: https://www.theguardian.com/uk-news/2017/may/10/university-ofmanchester-to-axe-171-staff-amid-brexit-concerns (accessed 23.05.2017).

Saeed, T. \& Johnson, D. (2016) Intelligence, Global Terrorism and Higher Education: Neutralising Threats or Alienating Allies? British Journal of Educational Studies, 64:1, 37-51, DOI: 10.1080/00071005.2015.1123216.

Shotwell, A. (2011) Knowing Otherwise: Race, Gender and Implicit Understanding, Pennsylvania: Penn State University Press.

Standing, G. (2015) The Precariat: the new dangerous classes, London: Bloomsbury.

Sukarieh, M. \& Tannock, S. (2016) The deradicalisation of education: terror, youth and the assault on learning. Race and Class 57 (4):22-38, DOI 10.1177/0306396815621236.

Taras, R. (2013) 'Islamophobia never stands still': race, religion, and culture, Ethnic and Racial Studies, 36:3, 417-433, DOI: 10.1080/01419870.2013.734388.

Tell MAMA (2016) The Geography of Anti-Muslim Hatred: Tell MAMA Annual Report 2015. Online: https://tellmamauk.org/geography-anti-muslim-hatred-2015-tell-mama-annual-report/ (accessed 04.05.2017).

Thomas, P. (2017) Changing experiences of responsibilisation and contestation within counter-terrorism policies: the British Prevent experience, Policy \& Politics, 45(3), 305-21, DOI: https://doi.org/10.1332/030557317X14943145195580.

Thomas, P. (2010) Failed and Friendless: The UK's 'Preventing Violent Extremism' Programme, British Journal of Politics and International Relations, 12 (3), 442-458, DOI: doi: 10.1111/j.1467-856X.2010.00422.x.

Universities UK (2016) Changing the Culture: Report of the Universities UK Taskforce examining violence against women, harassment and hate crime affecting university students. Online: http://www.universitiesuk.ac.uk/policy-andanalysis/reports/Documents/2016/changing-the-culture.pdf (accessed 09.03.2017).

Universities UK (2015) Student mental wellbeing in higher education: Good practice guide. Online: http://www.universitiesuk.ac.uk/policy-and-analysis/reports/Pages/student-mentalwellbeing-in-higher-education.aspx (accessed 25.05.2017).

University and College Union (2015) The Prevent duty: a guide for branches and members. Online: https://www.ucu.org.uk/media/7370/The-prevent-duty-guidance-for-branches-Dec15/pdf/ucu preventdutyguidance dec15.pdf (accessed 25.05.217). 
Versi, M. (2016) Brexit has given voice to racism - and too many are complicit, Guardian, 27 June. Online: https://www.theguardian.com/commentisfree/2016/jun/27/brexit-racism-eureferendum-racist-incidents-politicians-media (accessed 03.05.2017).

Walker, P. (2017) McDonnell: wiping out student loans is 'an ambition' for Labour, Guardian, 16 July. Online: https://www.theguardian.com/politics/2017/jul/16/john-mcdonnell-wiping-outstudent-loans-labour-jeremy-corbyn (accessed 21.07.2017).

YouGov UK (2016) One in four students suffer from mental health problems. Online: https://yougov.co.uk/news/2016/08/09/quarter-britains-students-are-afflicted-mental-hea/ (accessed 22.05.2017). 